\title{
ANALISIS USULAN PERBAIKAN MUTU PRODUK BERDASARKANMETODE SEVEN TOOLS DI PT.X
}

\author{
Muzakir $^{1)}$ \\ ${ }^{1)}$ Dosen Program Studi Teknik Industri Fakultas Teknik Universitas Teuku Umar \\ muzakir@utu.ac.id
}

\begin{abstract}
Have done analyzing the proposed improvement of product quality by method Seven Tools. From the calculation and analysis tools with seven methods that have been done there are three defects that occur on the production floor with the number of product defects due to a loose assembly of 196 pieces with a percentage of 59.57\%, and disability as a result of gluing the loose many as 82 pieces of disability (24, 92\%), the smallest of disability by 51 disability (15.50\%) which is due to lack of good raw material. The cause product defects occur due to human factors, machine, material, method, and the work environment, so that it can be said that the process is out of control. By using Seven tools in controlling the quality of products, can know and minimize the occurrence of product defects so that the quality and product quality under control.
\end{abstract}

Keywords : Seven tools, mutu produk, kecacatan.

\section{PENDAHULUAN}

Kemajuan yang dihadapi industri manufaktur dan pengolahan dalam hal merebut konsumen semakin ketat. Setiap perusahaan hendaknya secara terus-menerus meningkatkan mutu produk perusahaannya dengan selalu berusaha untuk mengurangi ketidaksesuaian, pemborosan, dan meningkatkan efisiensi dari keseluruhan proses mereka, sehingga proses dapat dikendalikan dengan tujuan untuk dapat mengurangi produk cacat.

Konsumen menginginkan produk yang berkualitas, untuk mewujudkan keinginan tersebut setiap perusahaan selalu berusaha untuk menjaga proses produksi yang mereka lakukan agar produk yang dihasilkan memiliki kualitas yang baik, kepuasan konsumen merupakan faktor yang sangat penting untuk keberlangsungan suatu perusahaan, karena itu perusahan dituntut untuk terus memperbaiki sistem produksinya untuk dapat memenuhi kepuasan konsumen sehingga tetap unggul dan mampu bersaing di pasaran.

Akan tetapi, dalam kenyataannya akan selalu ada ketidaksesuaian dari produk yang dihasilkan dan perusahaan harus mampu bersaing agar tetap bertahan dengan menunjukkan keunggulan dari setiap produk yang dihasilkan. Salah satu cara untuk menunjukkan keunggulannya yaitu peningkatan kualitas produk yang dihasilkan sesuai dengan keinginan konsumen.

PT. X merupakan sebuah perusahaan swasta yang bergerak di bidang manufaktur memproduksi daun pintu, daun jendela, kosen pintu, kosen jendela, serta bahan perlengkapan bangunan lain nya bahan baku yang di gunakan untuk pembuatan produk menggunakan kayu meuranti, seumantok, damar,dan kayu sembarang. Sistem produksi perusahaan bersifat make to order, yaitu produksi hanya berdasarkan pesanan pelanggan. Keadaan pelanggan yang semakin kritis dalam hal kualitas, mendorong perusahaan untuk lebih kerja keras dalam memperhatikan, mempertahankan dan meningkatkan kualitas produknya sehingga diperlukan peran pengendali produknya. Pembuatan produk di kerjakan oleh setiap pekerja dengan sistem borongan serta di setiap statiun kerja hanya di lakukan oleh satu orang pekerja. Adapun jumlah kecacatan rata-rata jumlah produk yang ditemukan pada bulan desember 2015 adalah 19,2\% rakitan yang longgar, 13,0\% pengeleman longgar, dan 11,3\% bahan baku kurang bagus dari 871 jumlah produk. Hasil produksi dipasarkan di daerah Aceh Barat dan sekitarnya.

Untuk standar mutu produk kusen pintu, kosen jendela, daun pintu, dan daun jendela berdasarkan SNI 01-6243.1-2000 yaitu persyaratan mutu terdiri dari jenis kayu, mutu penampilan, 
kadar air dan keteguhan rekat. Adapun ukuran kayu standar SNI 03-0675-1989 terpilih untuk untuk pembuatan kosen pintu dan kosen jendela di PT. X adalah $60 \mathrm{~mm} \times 100 \mathrm{~mm}, 60 \mathrm{~mm} \times 120 \mathrm{~mm}, 60$ $\mathrm{mm} \times 130 \mathrm{~mm}, 60 \mathrm{~mm} \times 150 \mathrm{~mm}, 80 \mathrm{~mm} \times 100 \mathrm{~mm}, 80 \mathrm{~mm} \times 120 \mathrm{~mm}, 80 \mathrm{~mm} \times 150 \mathrm{~mm}, 100 \mathrm{~mm}$ $\times 120 \mathrm{~mm}, 100 \mathrm{~mm} \times 150 \mathrm{~mm}$.

Ada juga ukuran standar SNI 03-0675-1989 untuk ukuran daun pintu dan daun jendela di UD .Yamay perabot adalah: Daun pintu: tebal jadi $33 \mathrm{~mm}, 35 \mathrm{~mm}$, lebar rangka $60 \mathrm{~mm}, 80 \mathrm{~mm}, 100$ $\mathrm{mm}, 120 \mathrm{~mm}, 150 \mathrm{~mm}, 180 \mathrm{~mm}, 200 \mathrm{~mm}$, lebar daun $720 \mathrm{~mm}, 820 \mathrm{~mm}$, dan tinggi daun $1960 \mathrm{~mm}$ dengan satuan milimeter. Daun jendela: tebal jadi $30 \mathrm{~mm}, 35 \mathrm{~mm}$, lebar rangka $60 \mathrm{~mm}, 80 \mathrm{~mm}, 100$ $\mathrm{mm}, 120 \mathrm{~mm}$, lebar daun $520 \mathrm{~mm}, 820 \mathrm{~mm}$, dan tinggi daun $1120 \mathrm{~mm}$.

Di dalam paper ini, akan dijelaskan mengenai analisis usulan perbaikan mutu produk berdasarkan metode seven tools.

\section{KAJIAN LITERATUR}

\subsection{Mutu}

Mutu merupakan hal yang penting dalam membangun dan mengelola fungsi produksi. Mutu akan mempengaruhi seluruh aktivitas perusahaan dari pemasok sampai konsumen dan dari manajemen produk sampai aspek dalam pemeliharaan peralatan. Tujuan akhir adalah menjadi perusahaan yang efektif dan efisien serta mempunyai keunggulan kompetitif terhadap produk yang dihasilkan.

Mutu memiliki banyak kriteria dan sangat tergantung pada konteks. Menurut Garvin dan Davis dalam Nasution (2005) mutu/kualitas merupakan suatu kondisi dinamis yang berhubungan dengan produk, jasa, manusia, proses dan lingkungan yang memenuhi atau melebihi harapan. Kualitas bukan hanya menekankan pada aspek hasil akhir, yaitu produk dan jasa tetapi juga menyangkut kualitas manusia, kualitas proses, dan kualitas lingkungan agar dapat memenuhi atau melebihi harapan konsumen.

Perusahaan harus menetapkan standarisasi dalam hal mutu dan mengaplikasikannya serta berusaha untuk mencapai spesifikasi yang direncanakan sambil terus-menerus melaksanakan penyempurnaan terhadap produk yang dihasilkan.

\subsection{Definisi Kualitas}

American National Standards Institute/American Society of Quality Control memberikan definisi kualitas adalah totalitas dari fitur dan karakteristik yang dimiliki oleh produk atau jasa yang melalui kemampuannya diharapkan memenuhi kebutuhan dan harapan pengguna. Untuk melihat kualitas sebuah produk/jasa diperlukan dimensi kualitas yang merupakan penghubung antara kebutuhan pelanggan dan karakteristik kualitas itu sendiri. Garvin (1987) memperluas dua belas dimensi kualitas yaitu sebagai berikut.

1. Performance, Karakteristik utama suatu produk/jasa.

2. Feature, Karakteristik tambahan yang memberi nilai tambah kepada konsumen.

3. Time, Lamanya waktu menunggu, mulai dari konsep sampai pembuatan produk baru, atau lamanya waktu penyelesaian pelayanan.

4. Reliability, Kondisi bebas dari kegagalan saat difungsikan.

5. Durability, Daya tahan hingga mencapai saat perlunya dilakukan penggantian.

6. Uniformity, Rendahnya variasi antara outcome proses yang berulang-ulang.

7. Consistency, Kesesuaian dengan dokumen, jadwal yang dijanjikan, standar-standar industri yang ditetapkan.

8. Serviceability, Kemampuan penyelesaian masalah dan komplain.

9. Aesthetics, Karakteristik yang berkaitan dengan penginderaan seperti keindahan, keserasian yang dirasakan sehingga menjadi daya tarik tersendiri bagi konsumen.

10. Persona linterface, Karakteristik yang berhubungan dengan keramah tamahan, penghargaan terhadap waktu, profesionalisme.

11. Harmless, Karakteristik yang berhubungan dengan keselamatan, kesehatan, dan lingkungan. 
12. Perceived quality, Ukuran-ukuran tidak langsung dari persepsi konsumen berupa reputasi, merek dan lain-lain.

\subsubsection{Perspektif Kualitas}

David Garvin (1994) mengidentifikasi adanya lima alternatif perspektif kualitas yang biasa digunakan, yaitu:

1. Transcendental Approach

2. $\quad$ Product-Based Approach

3. User-Based Approach

4. Manufacturing-Based Approach

5. Value-Based Approach

\subsubsection{Pengendalian Kualitas}

Dr. Juran (1962) mendukung pendelegasian pengendalian kualitas kepada tingkat paling bawah dalam organisasi melalui penempatan karyawan ke dalam swakendali (self-control). Pengendalian kualitas melibatkan beberapa aktivitas yaitu:

1. Mengevaluasi kerja aktual (actual performace).

2. Membandingkan aktual dengan target / sasaran.

3. Mengambil tindakan atas perbedaan antara aktual dan target.

Pada dasarnya performansi kualitas dapat ditentukan dan diukur berdasarkan karakteristik kualitas terdiri dari beberapa sifat atau dimensi yaitu:

1. Fisik seperti panjang, berat, diameter, tegangan, kekentalan.

2. Sensoris (berkaitan dengan panca indera) seperti rasa, penampilan, warna dan bentuk.

3. Orientasi waktu seperti keandalan, kemampuan pelayanan, kemudahan pemeliharaan, ketepatan waktu penyerahan produk.

4. Orientasi biaya seperti berkaitan dengan dimensi biaya yang menggambarkan harga atau ongkos dari suatu produk yang harus dibayarkan oleh konsumen.

Perlu dicatat pula bahwa informasi tentang kebutuhan pelanggan yang diperoleh melalui riset pasar harus didefenisikan dalam bentuk yang tepat dan pasti melalui atribut-atribut dan variablevariabel. Selanjutnya atribut-atribut dan variable-variabel dari produk inilah yang kemudian merupakan basis dari pengendalian proses statistika. Adapun yang menjadi pertimbangan dalam pengukuran performansi kualitas adalah: (1) Performansi (performance), berkaitan dengan aspek fungsional dari produk itu; (2) Features, berkaitan dengan pilihan-pilihan dan pengembangannya; (3) Keandalan, berkaitan dengan tingkat kegagalan dalam penggunaan produk itu; (4) Serviceability, berkaitan dengan kemudahan dan ongkos perbaikan; (5) Konformansi, berkaitan dengan tingkat kesesuaian produk terhadap spesifikasi yang telah ditetapkan sebelumnya berdasarkan keinginan pelanggan; (6) Durability, berkaitan dengan daya tahan atau masa pakai dari produk; (7) Estetika, berkaitan dengan desain dan kemasan dari produk itu dan (8) Kualitas yang dirasakan bersifat subjektif, berkaitan dengan perasaan pelanggan dalam mengonsumsi produk itu seperti meningkatkan gengsi, moral dan lain-lain.

\subsubsection{Tujuan Pengendalian Kualitas}

Seperti yang telah dikatakan bahwa maksud dari pengendalian mutu adalah agar spesifikasi produk yang telah ditentukan sebagai standar dapat tercermin dalam produk/hasil akhir. Secara terperinci dapat dikatakan bahwa tujuan dari pengendalian mutu adalah:

1. Agar barang hasil produksi dapat mencapai standar mutu yang telah ditentukan.

2. Mengusahakan agar biaya inspeksi dapat menjadi sekecil mungkin.

3. Mengusahakan agar biaya desain dari produk dan proses dengan menggunakan mutu produksi tertentu dapat sekecil mungkin.

4. Mengusahakan agar biaya produksi dapat menjadi sekecil mungkin.

\subsection{Metode Seven Tools}

Metode seven tools, merupakan salah satu alat statistik untuk mencari akar permasalahan kualitas, sehingga manajemen kualitas dapat menggunakan seven tools tersebut untuk mengetahui 
akar permasalahan terhadap produk yang mengalami cacat, serta dapat mengetahui penyebabpenyebab terjadinya cacat.

Menganalisa data untuk memecahkan masalah, maka dapat diperoleh dengan menggunakan teknik dasar pengendalian mutu terpadu yang umum disebut metode 7 tools (tujuh alat pengendalian mutu terpadu), yaitu:

1. Check Sheet (lembar pemeriksaan)

2. Histogram

3. Pareto Diagram

4. Cause effect diagram

5. Stratifikation

6. Scatter Diagram (diagram pencar)

7. Control Chart (peta control).

\section{METODOLOGI}

Jenis penelitian yang digunakan adalah penelitian deskriptif dengan menggunakan survey. Desain penelitian deskriptif digunakan untuk menggambarkan secara sistematis, faktual dan akurat mengenai fakta dan sifat yang melekat pada objek penelitian.Survay digunakan untuk meneliti gejala suatu kelompok atau perilaku individu.

Penelitian ini bertujuan untuk mendapatkan usulan perbaikan terhadap kualitas produk daun pintu, daun jendela, kosen pintu, dan kosen jendela yang sering mengalami kecacatan pada prosesnya.

Adapun rancangan penelitian ini adalah sesuai dengan flowchart sebagai berikut:

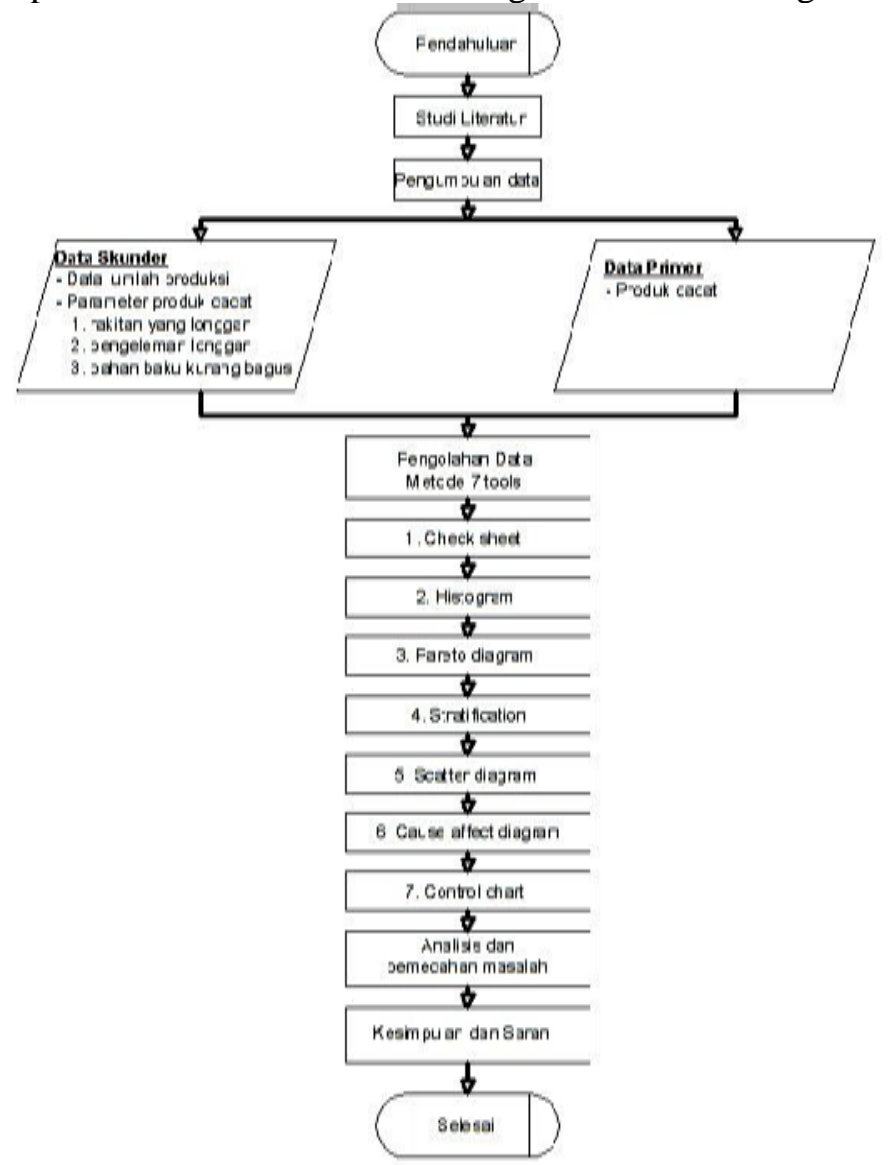

Gambar 5. Flowchart penelitian.

Data yang diperoleh merupakan data produksi selama 1 bulan yang berjumlah 801 buah, dimana dapat dipandang sudah memenuhi persyaratan data keseluruhan sampel. 


\section{HASIL DAN DISKUSI}

Data hasil produksi dari tanggal 18 Mei 2016 hingga 21 Juni 2016, diperoleh 3 (tiga) jenis kecacatan diantaranya yaitu rakitan longgar (X1), pengeleman longgar (X2) dan bahan baku yang kurang bagus (X3). Persentase kecacatan dapat dilihat pada tabel di bawah ini.

Tabel 1. Persentase Jumlah Kecacatan Produk.

\begin{tabular}{lccc}
\hline Jenis kecacatan & $\begin{array}{c}\text { total } \\
\text { kecacatan } \\
\text { (n) }\end{array}$ & $\begin{array}{c}\text { Persentase } \\
\text { kecacatan } \\
\text { (\%) }\end{array}$ & $\begin{array}{c}\text { Persentase } \\
\text { kecacatan } \\
\text { komulatif (\%) }\end{array}$ \\
\hline Rakitan longgar (X1) & 196 & 59,57 & 59,57 \\
Pengeleman longgar (X2) & 82 & 24,92 & 84,50 \\
Bahan baku kurang bagus (X3) & 51 & 15,50 & 100,00 \\
\hline Total & $\mathbf{3 2 9}$ & $\mathbf{1 0 0}$ & \\
\hline
\end{tabular}

Dari hasil pengamatan dapat diketahui bahwa kecacatan yang terjadi pada proses produksi selama tanggal 18 Mei 2016 sampai dengan tanggal 21 Juni 2016 pada gambar diagram pareto dapat dilihat bahwa ada 2 jenis kecacatan yang paling besar adalah kecacatan rakitan longgar (X1) dengan persentase 59,57\% dan pengeleman longgar (X2) dengan persentase 24,92\%. Untuk perhitungan korelasi antara kecacatan adalah hanya untuk kecacatan rakitan longgar (X1). Dengan demikian akan dibuat scatter diagram yang menunjukkan korelasi antara kecacatan rakitan longgar (X1) dan pengeleman longgar (X2).

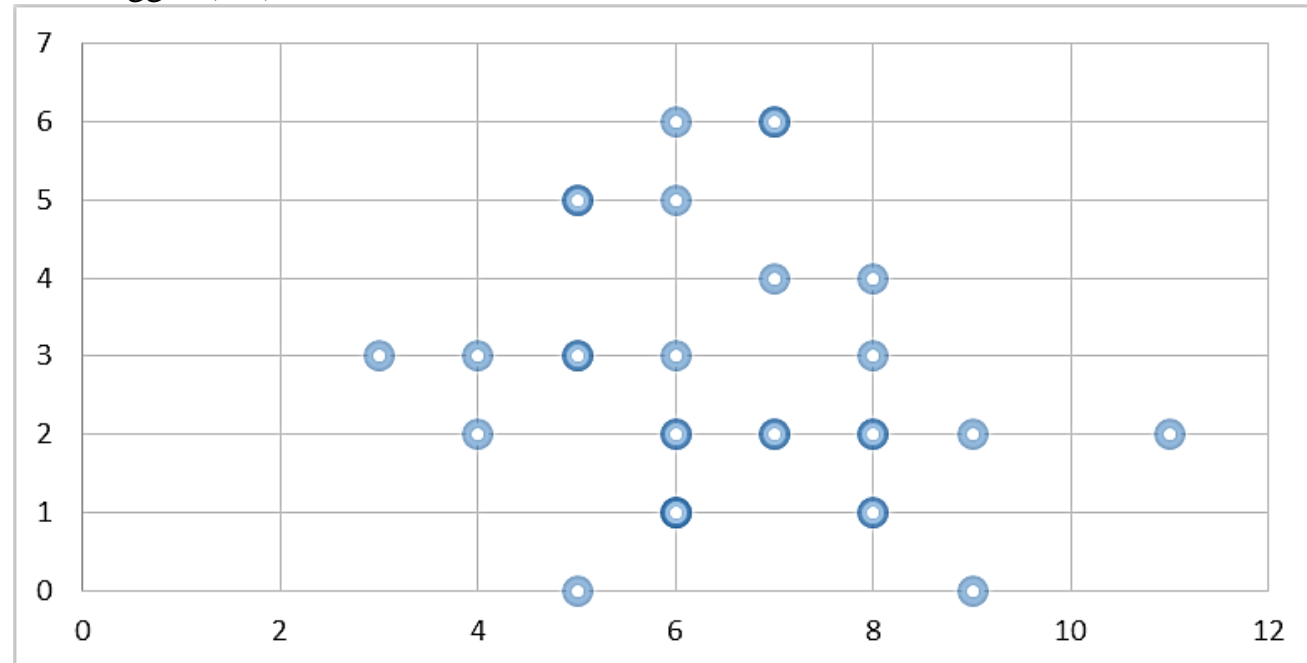

Gambar 6. Scatter diagram untuk kecacatan rakitan longgar dan pengeleman longgar.

Dengan menggunakan persamaan hubungan dua buah variabel, atau yang lebih dikenal sebagai korelasi diperoleh:

$$
\begin{aligned}
& r_{x y}=\frac{30(519)-(196 \times 82)}{\sqrt{\left[30 \times 1366-(196)^{2}\right] \times\left[30 \times 310-(82)^{2}\right]}} \\
& r_{x y}=-0,195
\end{aligned}
$$

Langkah selanjutnya yaitu membuat peta kendali (p-chart) untuk memperoleh gambaran tentang pengendalian kualitas. Untuk membuat peta kendali, dilakukan langkah-langkah sebagai berikut:

1. Menentukan CL (central line) untuk masing-masing kecacatan.

$$
\begin{aligned}
C L=\bar{P} \frac{\sum n p}{\sum n} \quad \text { dimana : } \quad \sum n p=\text { jumlah total yang rusak } \\
\quad \sum n=\text { total grup/sampel }
\end{aligned}
$$


2. Menghitung batas kendali atas (UCL) dan batas kendali bawah (LCL)

$$
\begin{aligned}
U C L & =\bar{p}+3 \sqrt{\frac{\bar{p}(1-\bar{p})}{n}} \\
L C L & =\bar{p}-3 \sqrt{\frac{\bar{p}(1-\bar{p})}{n}}
\end{aligned}
$$

keterangan:

$$
\begin{aligned}
& \bar{p}=\text { rata-rata kerusakan produk } \\
& n=\text { total grup/sampel }
\end{aligned}
$$

(sumber: Poerwanto, 2014).

Sehingga diperoleh hasil seperti yang ditunjukkan oleh tabel di bawah ini.

Tabel 2. Hasil perhitungan untuk peta kendali.

\begin{tabular}{clcccc}
\hline No. & \multicolumn{1}{c}{ Jenis Kecacatan } & Jumlah & CL & UCL & LCL \\
\hline 1 & Rakitan longgar (X1) & 196 & 6,5 & 9,8 & $-3,2$ \\
2 & Pengeleman longgar (X2) & 82 & 2,7 & 3,9 & $-1,5$ \\
3 & Bahan baku kurang bagus (X3) & 51 & 1,7 & 2,3 & $-1,1$ \\
\hline
\end{tabular}

Sehingga dari hasil yang ditunjukkan oleh tabel 2, dapat dibuat peta kendalinya untuk masingmasing kecacatan sebagai berikut:

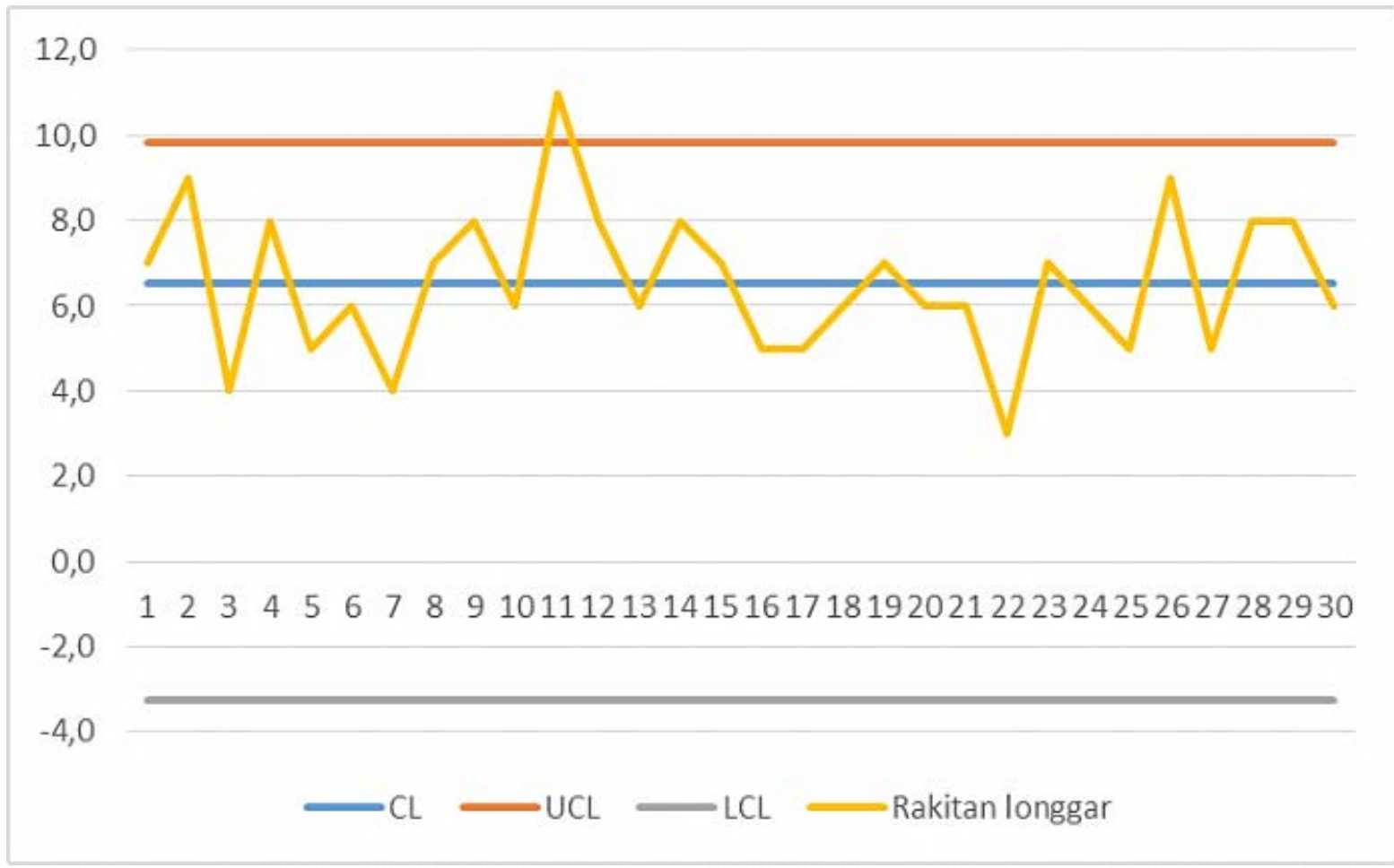

(a) 


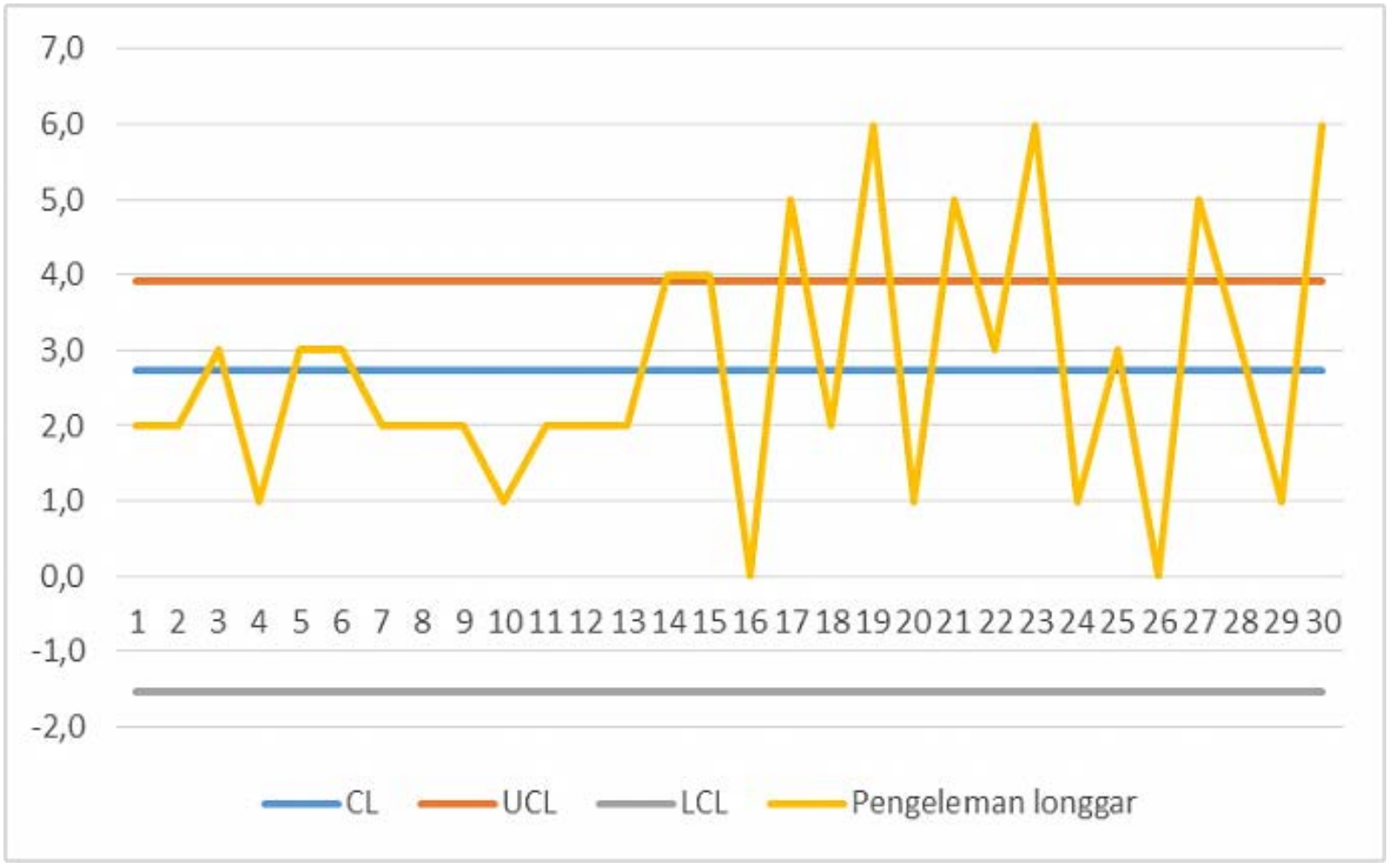

(b)

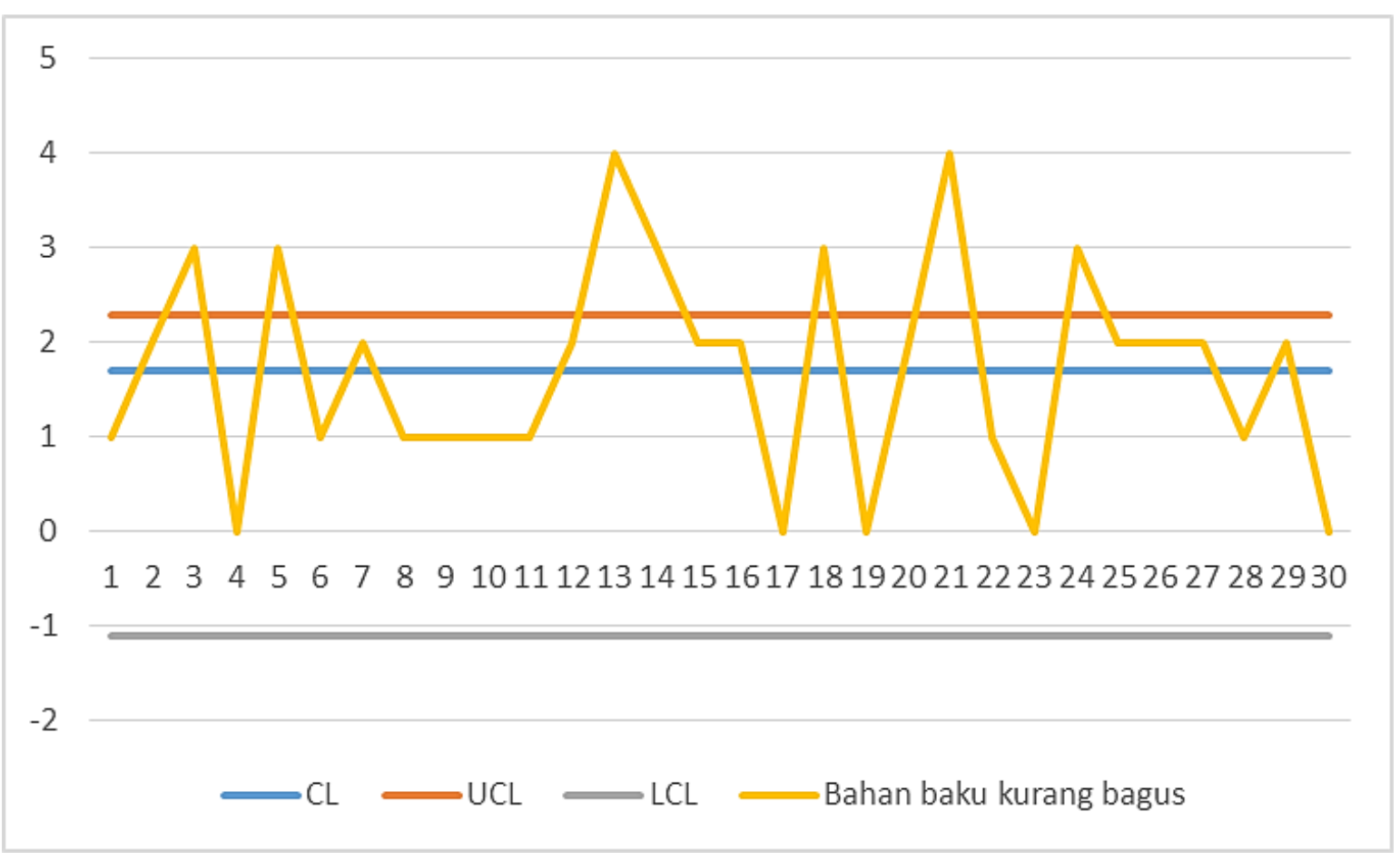

(c)

Gambar 7. Diagram p-chart untuk kecacatan: (a) rakitan longgar, (b) pengeleman longgar dan (c) bahan baku yang kurang bagus. 


\section{KESIMPULAN}

Dari hasil perhitungan dan analisis dengan metode seven tools yang telah dilakukan terdapat 3 kecacatan yang terjadi di lantai produksi dengan jumlah kecacatan produk akibat rakitan longgar sebanyak 196 buah dengan persentase sebesar 59,57\%, kemudian kecacatan akibat pengeleman longgar sebanyak 82 buah kecacatan (24,92\%), kecacatan terkecil sebanyak 51 kecacatan (15,50\%) yaitu akibat bahan baku kurang bagus. Penyebab kecacatan produk terjadi karena faktor manusia, mesin, bahan baku, metode, dan lingkungan kerja, sehingga bisa dikatakan bahwa proses tidak terkendali. Karena terdapat titik yang berada di luar batas kendali dan yang lain berada di dalam batas kendali.

Dengan menggunakan metode Seven tools dalam mengendalikan kualitas produk, dapat mengetahui dan meminimalisir terjadinya kecacatan produk sehingga kualitas dan mutu produk tetap terkontrol.

\section{DAFTAR PUSTAKA}

Fakri, A. 2010. Usulan Perbaikan Mutu Produk Rubber Smoke Sheet (RSS) Berdasarkan Metode Kaizen Di PT. Perkebunan Nusantara III Kebun Gunung Para. Medan, USU.

Assauri, Soyjan. 2008. Manajemen Produksi dan Operasi, Jakarta: LPFEUI. diakses dari www.aslilaspot.co.idh.blog /2013/02/pengertian-mutu-produk.html.

Garvin, D. 1994. Kualitas Produk : Alat Strategi Yang Penting. Free Press.

Juran. 1962. Quality control handbook. New York, McGraw-Hill.

Even, R.. 2015. Pengendalian Kualitas Untuk Mereduksi Kecacatan Produk Dan Meningkatkan Kecepatan Produksi Dengan Pendekatan Metode Lean Six Sigma Pada PT. Bamindo Agrapersada. Medan, USU.

Garvin, D. A. 1987. Managing Quality. New York, The Free Press.

Poerwanto, G., Hendra. 2014. Membahas konsep dan cara membuat Peta Kendali (Control Chart) X bar dan R Chart. (www.aslilaspot.co.idh.blog).

Nasution. 2005. Total Quality Management. (www.aslilaspot.co.idh.blog /2013/02/pengertian -mutuproduk.html).

Simorangkir. 2015. Analisis Sistem Pengendalian Mutu Produk Pintu Berbahan Baku Kayu Dengan Menggunakan Pendekatan Lean Six Sigma Pada PT. Sumatera Timberindo Industry. Medan, USU. 